Clinical Research Paper

\title{
Effect of parental physiological conditions and assisted reproductive technologies on the pregnancy and birth outcomes in infertile patients
}

\author{
Xinqi Zhong ${ }^{1,2}$, Jianqiao Liư ${ }^{3}$, Qiliang Cui ${ }^{2}$, Shaozhen Liang ${ }^{2}$, Yuanqing Lin², Haiying \\ Liu ${ }^{3}$ and Qiyi Zeng ${ }^{1}$ \\ ${ }^{1}$ Department of Pediatrics, Zhujiang Hospital, Southern Medical University, Guangzhou, Guangdong, China \\ 2 Department of Pediatrics, the Third Affiliated Hospital of Guangzhou Medical University, Guangzhou, Guangdong, China \\ 3 Department of Reproductive Medicine, the Third Affiliated Hospital of Guangzhou Medical University, Guangzhou, \\ Guangdong, China \\ Correspondence to: Qiyi Zeng, email: zengay_zj@163.com \\ Keywords: birth defects, assisted reproductive technologies, pregnancy, infertile, birth outcome \\ Received: July 29, $2016 \quad$ Accepted: September 29, $2016 \quad$ Published: October 10, 2016
}

\section{ABSTRACT}

Assisted reproductive technologies (ART) are widely used to treat infertility. Emerging evidence suggested that ART was associated with perinatal or neonatal problems, however, little is known about the ART related risk factors. Here using 21136 ART cases, we determined the impacts of parental physiological conditions in the ART mediated pregnancy outcomes. In addition, we further evaluated the effects of three different ART methods (frozen-thawed embryo transfer [FET], in vitro fertilization [IVF] and intracytoplasmic sperm injection [ICSI]) in the pregnancy and birth outcomes in ART mediated pregnancy. Our data revealed that older parental age increases the risks of abortion, preterm birth and low body weight birth. Higher maternal BMI (Body mass index) level correlates with higher abortion rate. Moreover, pregnancy with multiple fetuses has severer adverse outcomes compared to singleton pregnancy. Among the three ART methods, ICSI is associated with lower ratios of ectopic pregnancy, abortion and deformity compared to FET and IVF. Our study revealed new clinical insights into the ART related risk factors and suggested that both the parental physiological conditions and ART methods should be evaluated to develop better ART mediated infertility treatments.

\section{INTRODUCTION}

ART mediated infertility treatments have brought tremendous benefits to the infertile patients [1]. However, emerging perinatal or neonatal problems have been reported to be associated with ART [2-7]. Recent studies revealed ART as an independent factor that contributes to the poor maternal and neonatal outcomes [4-6, 8-10]. For example, a systematic review of 25 studies suggested that, infants born with ART have a significant $30-40 \%$ increased risk of birth defects compared to those born in spontaneous pregnancy [8]. In addition, ART is associated with increased risk of as low birth weight (LBW) $[2,3]$, preterm birth (PTB) [3], small gestational age [11], and childhood cancers [12].
Currently little is known about the factors associated with ART risks. Some studies showed that the social statuses, pregnancy related characteristics and medical conditions are different between the ART treated mothers and the non-ART treated mothers [13-15], however, whether the above difference contributes to the increased risk of adverse pregnancy outcomes is still inconclusive. In addition, different assisted reproduction techniques might have different successful rates and risks, while at this point whether different ART techniques are associated with different risks of bad clinical outcomes remains to be characterized.

Characterization of the physiological and technical factors that associated the increased risks of ART is crucial for the development of better ART treatment strategies for 
infertile patients. In this study, we studied the associations between parental physiological conditions and pregnancy/ birth outcomes in 21136 ART cases. In addition, we further compared the pregnancy/birth outcomes in ART cases that performed with three different ART methods (FET, IVF, and ICSI). Our data provided novel insights into the ART related risk factors and could potentially be used for clinical guidelines in ART treatment for infertile patients.

\section{MATERIALS AND METHODS}

\section{Study population}

ART cases performed between Jan 2010 and Dec 2014 in Reproductive Medicine Center of Guangzhou Medical Centre for Critical Pregnant Women in Guangzhou Institute of Obstetrics and Gynecology, Guangzhou, China, were used for this study. 21136 ART cases that had detail information about patient physiological conditions, treatment processes, birth outcomes were included for the study. Patients with other major health problems, without reliable information, did not complete follow up and patients who did not sign the consents form were excluded. The ART cases that used donor ovocytes or sperms were excluded. All the patients are Asian. The study protocol was approved by the Institutional Ethic Committee of the Hospital. Written informed consents were obtained from all patients before collecting the clinical information.

\section{Data collection}

Patient and pregnancy data were recorded by the hospital specialists from patient's first consultation to final neonatal birth. Data were retrieved from the hospital records to study the ART related risk factors. Patients' physiological conditions, including parental ages, infertile types and years, mother's BMI, pregnancy outcomes (ectopic pregnancy, abortion, premature birth, deformity and low birth weight infants) were used to evaluate the role of physiological conditions in ART mediated pregnancy outcomes. In addition, the clinical outcomes of ART cases performed using three different ART methods including IVF, ICSI and FET were investigated to determine the effect of different ART methods in pregnancy and birth outcomes.

\section{Definitions of birth outcomes}

Ectopic pregnancy refers to the pregnancy that occurs outside the uterus. Abortion means the pregnancy is terminated during the first 28 weeks of pregnancy. Preterm birth is defined as a premature birth that takes place three weeks before the due day (before the $37^{\text {th }}$ week of pregnancy). Deformity means the fetus that has deformed body parts. Low body weight birth is defined as a birth in which the infant's weight is less than $2,500 \mathrm{~g}$.

\section{Statistical analysis}

SPSS17.0 software was used for the statistics analysis. Measurement data were presented as mean \pm standard deviation, and enumeration data were presented by frequency. Pearson $\chi 2$ test or $\chi 2$ test with continuity correction was used for the comparison of enumeration data. Chi-square test of four-fold table and contingency table were used for the analysis of two groups and multiple groups of enumeration data, separately. A $p$ value $<0.05$ was considered as statistically significant.

\section{RESULTS}

\section{The pregnancy outcome in the ART cases}

In the 21136 ART cases, the average maternal age was $32.0 \pm 4.4$ (range: $20-49$ ), average paternal age was $34.5 \pm 5.3$ (range: $21-78$ ), and the average infertile years was $4.9 \pm 3.3$ (range: 1-23). After ART treatments, 10139 patients successfully achieved pregnancy, accounting for $48.0 \%$ of the total cases. Of the 10139 pregnancies, there were 9819 cases $(96.8 \%$ of total pregnancies) of intrauterine pregnancies, 283 cases $(2.8 \%)$ of ectopic pregnancies and 37 cases $(0.4 \%)$ of simultaneously intrauterine and ectopic pregnancies. There were 8066 cases of successful delivery (38.2\% of total ART cases), including 5470 (67.8\%) singletons and 2596 (32.2\%) multiple births. Totally 10695 babies (5748 male and 4947 female) were born from the 8066 deliveries, among those there were 3214 cases of low body weight and 116 cases of deformities.

\section{The clinical factors affecting the successful rate of pregnancy}

To determine the ART risk factors, we first investigated the association between the patients' physiological conditions and the pregnancy outcomea in the 21136 ART cases. As shown in Table.1, the patients with primary infertility had significant higher ratio $(49.1 \%)$ of successful pregnancy than those with secondary infertility $(46.8 \%)$. The pregnancy rate was significant higher in families with only one infertile parent compared to those families in which both parents were infertile. In addition, older parental age, higher maternal BMI and longer infertile time were significantly associated with lower rates of pregnancy. 
Table 1: Influence of parental physiological conditions in ART clinical pregnancy

\begin{tabular}{|c|c|c|c|c|c|c|c|}
\hline & \multicolumn{2}{|c|}{ Pregnant } & \multicolumn{2}{|c|}{ Not pregnant } & \multirow{2}{*}{ Total } & \multirow{2}{*}{$\chi^{2}$} & \multirow{2}{*}{$p$} \\
\hline & $\mathrm{n}$ & $\%$ & n & $\%$ & & & \\
\hline Infertile Types & & & & & & 10.86 & 0.001 \\
\hline Primary & 5240 & 49.1 & 5434 & 50.9 & 10674 & & \\
\hline Secondary & 4899 & 46.8 & 5563 & 53.2 & 10462 & & \\
\hline Infertile Gender & & & & & & 20.57 & $<0.001$ \\
\hline Male & 1459 & 49.1 & 1513 & 50.9 & 2972 & & \\
\hline Female & 6940 & 48.6 & 7332 & 51.4 & 14272 & & \\
\hline Both & 1740 & 44.7 & 2152 & 55.3 & 3892 & & \\
\hline Maternal Age & & & & & & 452.16 & $<0.001$ \\
\hline$<35$ & 8002 & 52.5 & 7235 & 47.5 & 15237 & & \\
\hline$\geq 35$ & 2137 & 36.2 & 3762 & 63.8 & 5899 & & \\
\hline Maternal BMI & & & & & & 20.5 & 0.000 \\
\hline$<24$ & 7920 & 49.8 & 7972 & 50.2 & 15892 & & \\
\hline$\geq 24$ & 1738 & 45.7 & 2061 & 54.3 & 3799 & & \\
\hline Paternal Age & & & & & & 216.82 & $<0.001$ \\
\hline$<35$ & 6073 & 52.6 & 5477 & 47.4 & 11550 & & \\
\hline$\geq 35$ & 4066 & 42.4 & 5520 & 57.6 & 9586 & & \\
\hline Infertile Years & & & & & & 146.20 & $<0.001$ \\
\hline$<2$ & 1229 & 52.7 & 1103 & 47.3 & 2332 & & \\
\hline $2-3$ & 3247 & 51.6 & 3047 & 48.4 & 6294 & & \\
\hline $4-5$ & 2547 & 49.2 & 2626 & 50.8 & 5173 & & \\
\hline$\geq 6$ & 3116 & 42.5 & 4221 & 57.5 & 7337 & & \\
\hline Total & 10139 & & 10997 & & 21136 & & \\
\hline
\end{tabular}

Table 2: Influence of maternal age on pregnancy and birth outcome

\begin{tabular}{|c|c|c|c|c|c|c|c|c|}
\hline & & \multicolumn{2}{|c|}{$<35$} & \multicolumn{2}{|c|}{$\geq 35$} & \multirow{2}{*}{ total } & \multirow{2}{*}{$\chi^{2}$} & \multirow{2}{*}{$p$} \\
\hline & & $\mathbf{n}$ & $\%$ & $\mathbf{n}$ & $\%$ & & & \\
\hline \multirow{3}{*}{$\begin{array}{c}\text { ectopic } \\
\text { pregnancy }\end{array}$} & yes & 248 & 3.1 & 72 & 3.4 & 320 & 0.40 & 0.526 \\
\hline & no & 7754 & 96.9 & 2065 & 96.6 & 9819 & & \\
\hline & total & 8002 & 100.0 & 2137 & 100.0 & 10139 & & \\
\hline \multirow{3}{*}{ abortion } & yes & 1106 & 13.8 & 468 & 21.9 & 1574 & 83.93 & 0.000 \\
\hline & no & 6896 & 86.2 & 1669 & 78.1 & 8565 & & \\
\hline & total & 8002 & 100.0 & 2137 & 100.0 & 10139 & & \\
\hline \multirow{3}{*}{ preterm birth } & yes & 1716 & 26.3 & 371 & 23.8 & 2087 & 4.40 & 0.036 \\
\hline & no & 4799 & 73.7 & 1191 & 76.2 & 5990 & & \\
\hline & total & 6515 & 100.0 & 1562 & 100.0 & 8077 & & \\
\hline \multirow{3}{*}{ deformity } & yes & 89 & 1.4 & 18 & 1.2 & 107 & 0.42 & 0.515 \\
\hline & no & 6434 & 98.6 & 1541 & 98.8 & 7975 & & \\
\hline & total & 6523 & 100.0 & 1559 & 100.0 & 8082 & & \\
\hline \multirow{3}{*}{$\begin{array}{c}\text { low body } \\
\text { weight birth }\end{array}$} & yes & 1830 & 28.1 & 363 & 23.3 & 2193 & 14.91 & 0.000 \\
\hline & no & 4680 & 71.9 & 1197 & 76.7 & 5877 & & \\
\hline & total & 6510 & 100.0 & 1560 & 100.0 & 8070 & & \\
\hline
\end{tabular}


Table 3: Influence of maternal BMI on pregnancy and birth outcome

\begin{tabular}{ccccccccc}
\hline & & \multicolumn{2}{c}{$<\mathbf{2 4}$} & \multicolumn{2}{c}{$\geq \mathbf{2 4}$} & \multirow{2}{*}{ total } & \multirow{2}{*}{$\mathbf{2}$} & $\boldsymbol{p}$ \\
\cline { 2 - 6 } ectopic & yes & 249 & 3.1 & 47 & 2.7 & 296 & 0.93 & .336 \\
pregnancy & no & 7671 & 96.9 & 1691 & 97.3 & 9362 & & \\
& total & 7920 & 100.0 & 1738 & 100.0 & 9658 & & \\
\hline \multirow{4}{*}{ abortion } & yes & 1180 & 14.9 & 317 & 18.2 & 1497 & 12.14 & .000 \\
& no & 6740 & 85.1 & 1421 & 81.8 & 8161 & & \\
& total & 7920 & 100.0 & 1738 & 100.0 & 9658 & & \\
\hline \multirow{4}{*}{ preterm birth } & yes & 1645 & 25.9 & 357 & 26.6 & 2002 & 0.28 & .596 \\
& no & 4715 & 74.1 & 987 & 73.4 & 5702 & & \\
& total & 6360 & 100.0 & 1344 & 100.0 & 7704 & & \\
\hline \multirow{2}{*}{ deformity } & yes & 86 & 1.4 & 18 & 1.3 & 104 & 0.00 & .981 \\
& no & 6282 & 98.6 & 1323 & 98.7 & 7605 & & \\
& total & 6368 & 100.0 & 1341 & 100.0 & 7709 & & \\
\hline \multirow{2}{*}{ low body } & yes & 1759 & 27.7 & 349 & 26.0 & 2108 & 1.47 & .225 \\
weight birth & no & 4598 & 72.3 & 991 & 74.0 & 5589 & & \\
& total & 6357 & 100.0 & 1340 & 100.0 & 7697 & & \\
\hline
\end{tabular}

\section{Association between maternal age and birth outcomes}

Next we investigated the potential association between maternal age and the pregnancy/birth outcomes (Table 2) in the ART cases. The ratios of different pregnancy and birth outcomes (ectopic pregnancy, abortion, preterm birth, low body weight birth and deformity) were evaluated in two different maternal age groups. As shown in Table 2, the ratio of abortion in older age ( $\geq 35)$ group was $21.9 \%$, significantly higher than the ratio $(13.8 \%)$ in the younger age $(<35)$ group. While the ratios of low body weight and preterm birth were significantly lower in the older age group. There was no statistically significant difference in the ratio of ectopic pregnancy and deformity in the two different age groups.

\section{The influence of maternal BMI levels on the birth outcomes}

The parents were separated into two different groups (BMI high and BMI low) to study the association between maternal BMI levels and pregnancy/birth outcomes (Table 3). The ratio of abortion in BMI high ( $\geq 24)$ group was $18.2 \%$, which was significantly higher compared to $14.9 \%$ in BMI low $(<24)$ group. There's no statistically significant difference in ectopic pregnancy, preterm birth, deformity and low body weight between the BMI high and low groups.

\section{The influence of fetus numbers on the birth outcomes}

ART treatments often result in multiple fetuses in the pregnancy, we further determined the association between fetus numbers and the pregnancy/birth outcomes in our ART cases (Table 4). The ratio of ectopic pregnancy in patients with multiple fetuses was $1.3 \%$, significantly lower than $4.6 \%$ in patients with singleton. The ratio of abortion was also significantly lower in patients with multiple fetus $(10.2 \%)$ compared to those with singleton $(21.1 \%)$. On the other hand, in the patients with multiple fetuses, the ratios of preterm birth, deformity and low body weight birth were $49 \%, 2.0 \%$ and $57.5 \%$, which were significantly higher than the ratios in the patients with singleton $(9.2 \%, 0.9 \%$ and $6.7 \%$, respectively).

\section{The influence of different ART methods on the birth outcomes}

We next investigated whether different ART treatment methods could affect the pregnancy outcomes. There different ART methods were used for the treatment of infertile patients. As shown in Table 5, the ratios of ectopic pregnancy, abortion and deformity were significant lower in the ICSI group compared to the FET and IVF groups. On the other hand, the ratio of low body weight birth was significantly lower in the FET group compared to the other two groups. There's no statistically significant difference in the ratio of preterm birth in the three groups.

\section{DISCUSSION}

More and more evidence suggested that ART is associated with bad pregnancy and birth outcomes, however, little is known about the factors that are correlated with the pregnancy and birth outcomes in the ART treated patients. In this study, we studied the potential ART risk related factors with a total of 21136 ART cases in our hospital from 2010 to 2014. ART is associated with higher ratios of preterm birth $(25.8 \%)$ and low body 
Table 4: Influence of fetus number on pregnancy and birth outcome

\begin{tabular}{|c|c|c|c|c|c|c|c|c|}
\hline & & \multicolumn{2}{|c|}{ singleton } & \multicolumn{2}{|c|}{ multiple fetuses } & \multirow{2}{*}{ total } & \multirow{2}{*}{$x^{2}$} & \multirow{2}{*}{$p$} \\
\hline & & n & $\%$ & $\mathbf{n}$ & $\%$ & & & \\
\hline \multirow{3}{*}{$\begin{array}{c}\text { ectopic } \\
\text { pregnancy }\end{array}$} & yes & 216 & 4.6 & 39 & 1.3 & 255 & 62.40 & 0.000 \\
\hline & no & 4440 & 95.4 & 2940 & 98.7 & 7380 & & \\
\hline & total & 4656 & 100.0 & 2979 & 100.0 & 7635 & & \\
\hline \multirow{3}{*}{ abortion } & yes & 982 & 21.1 & 304 & 10.2 & 1286 & 153.71 & 0.000 \\
\hline & no & 3674 & 78.9 & 2675 & 89.8 & 6349 & & \\
\hline & total & 4656 & 100.0 & 2979 & 100.0 & 7635 & & \\
\hline \multirow{3}{*}{$\begin{array}{l}\text { preterm } \\
\text { birth }\end{array}$} & yes & 310 & 9.2 & 1251 & 49.0 & 1561 & 1184.00 & 0.000 \\
\hline & no & 3058 & 90.8 & 1303 & 51.0 & 4361 & & \\
\hline & total & 3368 & 100.0 & 2554 & 100.0 & 5922 & & \\
\hline \multirow{3}{*}{ deformity } & yes & 32 & 0.9 & 51 & 2.0 & 83 & 11.58 & 0.001 \\
\hline & no & 3340 & 99.1 & 2501 & 98.0 & 5841 & & \\
\hline & total & 3372 & 100 & 2552 & 100 & 5924 & & \\
\hline \multirow{3}{*}{$\begin{array}{c}\text { low body } \\
\text { weight } \\
\text { birth }\end{array}$} & yes & 226 & 6.7 & 1467 & 57.5 & 1693 & 1828.62 & 0.000 \\
\hline & no & 3136 & 93.3 & 1086 & 42.5 & 4222 & & \\
\hline & total & 3362 & 100.0 & 2553 & 100.0 & 5915 & & \\
\hline
\end{tabular}

Table 5: Influence of different ART treatments on the pregnancy and birth outcome

\begin{tabular}{|c|c|c|c|c|c|c|c|c|c|c|}
\hline & & \multicolumn{2}{|c|}{ FET } & \multicolumn{2}{|c|}{ IVF } & \multicolumn{2}{|c|}{ ICSI } & \multirow{2}{*}{ total } & \multirow{2}{*}{$\chi^{2}$} & \multirow{2}{*}{$p$} \\
\hline & & $\mathbf{n}$ & $\%$ & n & $\%$ & $\mathbf{n}$ & $\%$ & & & \\
\hline \multirow{3}{*}{$\begin{array}{l}\text { ectopic } \\
\text { pregnancy }\end{array}$} & yes & 94 & 3.2 & 204 & 3.4 & 22 & 1.8 & 320 & 9.49 & 0.009 \\
\hline & no & 2871 & 96.8 & 5723 & 96.6 & 1225 & 98.2 & 9819 & & \\
\hline & total & 2965 & 100.0 & 5927 & 100.0 & 1247 & 100.0 & 10139 & & \\
\hline \multirow{3}{*}{ abortion } & yes & 493 & 16.6 & 916 & 15.5 & 165 & 13.2 & 1574 & 7.77 & 0.021 \\
\hline & no & 2472 & 83.4 & 5011 & 84.5 & 1082 & 86.8 & 8565 & & \\
\hline & total & 2965 & 100.0 & 5927 & 100.0 & 1247 & 100.0 & 10139 & & \\
\hline \multirow{3}{*}{$\begin{array}{l}\text { preterm } \\
\text { birth }\end{array}$} & yes & 579 & 25.1 & 1251 & 26.4 & 257 & 25.0 & 2087 & 1.81 & 0.406 \\
\hline & no & 1728 & 74.9 & 3490 & 73.6 & 772 & 75.0 & 5990 & & \\
\hline & total & 2307 & 100.0 & 4741 & 100.0 & 1029 & 100.0 & 8077 & & \\
\hline \multirow{3}{*}{ deformity } & yes & 42 & 1.8 & 57 & 1.2 & 8 & 0.8 & 107 & 7.21 & 0.027 \\
\hline & no & 2268 & 98.2 & 4687 & 98.8 & 1020 & 99.2 & 7975 & & \\
\hline & total & 2310 & 100.0 & 4744 & 100.0 & 1028 & 100.0 & 8082 & & \\
\hline \multirow{3}{*}{$\begin{array}{l}\text { low body } \\
\text { weight birth }\end{array}$} & yes & 533 & 23.1 & 1386 & 29.3 & 274 & 26.6 & 2193 & 29.80 & 0.000 \\
\hline & no & 1772 & 76.9 & 3349 & 70.7 & 756 & 73.4 & 5877 & & \\
\hline & total & 2305 & 100.0 & 4735 & 100.0 & 1030 & 100.0 & 8070 & & \\
\hline
\end{tabular}

weight birth (27.2\%) (Table 2$)$ than the ratios $(4.37 \%$ and $6.1 \%$ ) reported in natural pregnancies $[16,17]$. The ratio of deformity in our ART cases was $1.32 \%$ (Table 2 ), which is very similar to the deformity ratio $(1.35 \%)$ in the natural pregnancies in China [18].

We then studied the factors that are associated with successful pregnancy and revealed that primary infertility patients have better chance of pregnancy than the secondary infertility patients. In addition, patients with older age, higher BMI and longer infertile time have less ratio of pregnancy after ART treatments. This suggested that the successful rate of pregnancy in ART treatment patients is affected by different parental physiological conditions. Previously, it was reported that the successful rate of ART in $\geq 40$ years old patients was significantly lower than patients younger than 40 [19-21]. In our study, we used 35 years old as the maternal age cutoff because 25-35 years is the optimal age for female to have babies. Our result also revealed that advanced maternal age has negative impact on ART mediated pregnancy. In addition, our results were consistent with the previous reports that obesity increases the risk of abortion in ART pregnancy 
$[22,23]$. Old maternal age and high BMI might be associated with increased chance of ovarian dysfunction; longer duration of infertility might cause stronger pelvic adhesions, therefore decreasing the chance of successful pregnancy.

We next studied the influence of maternal physiological conditions in the birth outcomes in the ART mediated pregnancies. We found that older maternal age was associated with higher ratio of abortion, while interestingly, the ratios of some other bad birth outcomes including low body weight and preterm birth were significantly lower in the older patients. Similarly, higher maternal BMI level and longer duration of infertility were significantly associated with higher chance of abortion but lower ratio of low body weight birth in the ART cases. Older maternal age, higher maternal BMI, longer duration of infertility are usually associated with weakened ovarian function, mis-regulated endometrial morphology and function, increased risks of chromosomal aberrations and decreased uterine receptivity, creating an unfavorable environment for the baby growth $[24,25]$. Therefore, the chance for the babies with minor defects (preterm birth and low body weight) to survive during pregnancy decreases, resulting in higher ratio of abortion and accordingly lower ratios of preterm birth and low body weight birth. All these data suggested that the optimal maternal physiological conditions are critical for successful pregnancies and good birth outcomes in the ART treated patients.

In addition to the parental physiological conditions, different ART methods can also affect the pregnancy and birth outcomes in the infertile patients. In this study, we evaluated the effect of three different ART methods, including FET, IVF and ICSI, in the birth outcomes in our ART cases. It has been controversial about the whether there is significant difference in the clinical outcomes between the frozen embryo transfer and fresh embryo transfer ART methods. For example, a recent study suggested that the fresh embryo transfer methods had better pregnancy outcomes than the frozen embryo transfer method [26], while others revealed that FET could reduce the ovarian hyperstimulation syndrome risks and improve birth outcomes [27-29]. In our study, we performed a comprehensive analysis of multiple aspects of birth outcomes and found that FET treatment is associated with significantly lower ratio of low body weight birth but higher ratio of deformity compared to the fresh embryo transfer treatments. Our results suggested that the frozenthaw process could have both positive and negative effects on the birth outcomes, which could partially explain the controversies about the role of embryo frozen in ART because different early studies only investigated certain aspects of the birth outcomes [26-29].

We also compared the birth outcomes in the two fresh embryo transfer ART methods (IVF and ICSI). Our data revealed that patients treated with ICSI have significantly lower ratios of ectopic pregnancy, abortion and deformity, suggesting that ICSI is associated with better birth outcomes than IVF and FET. ICSI is a ART method in which a single function sperm is injected into the cytoplasm of the egg for the fertilization, and is commonly used to treat the infertile male that have too few motile and morphologically normal sperm [30, 31]. Our finding revealed that ICSI is associated with better birth outcomes compared to conventional IVF, which is consistent with conclusion from a recent Norwegian national population-based cohort study [32].

There are limitations in this study: first, all the study subjects were from the same hospital, the successful rate of pregnancy might be affected by the doctors' medical skills and the hospital's medical facility conditions. Second, when comparing the pregnancy outcomes in ART mediated pregnancies to the natural pregnancies, we used the published natural pregnancy data, the natural pregnancy data from the same hospital will be better for the comparison.

Overall, we revealed that the parental age, maternal BMI, fetus numbers and different ART methods have significant impacts on the clinical pregnancy and birth outcomes in the ART treated infertile patients. Our study provided novel insights into the ART related risk factors and could serve as clinical guidelines to prevent and reduce the risk of bad outcomes in the ART mediated infertile treatments.

\section{ACKNOWLEDGMENTS}

This work was supported in part by the Guangzhou Science and Technology Program (2014Y2-00053) to Third Affiliated Hospital of Guangdong Medical University.

\section{CONFLICTS OF INTEREST}

No conflicts of interest are declared.

\section{Author Contributions}

X.Z collected and analyzed the data and wrote the manuscript; J.L and Q.C supervised the data collection and the ART database management; S.L, Y.L, and H.L collected the patient and pregnancy data for the ART database. Q.Z supervised the study design, data analysis and manuscript preparation.

\section{REFERENCES}

1. Menezo YJ, Veiga A, Pouly JL. Assisted reproductive technology (ART) in humans: facts and uncertainties. Theriogenology. 2000; 53: 599-610.

2. Schieve LA, Meikle SF, Ferre C, Peterson HB, Jeng G, Wilcox LS. Low and very low birth weight in infants 
conceived with use of assisted reproductive technology. $\mathrm{N}$ Engl J Med. 2002; 346: 731-7. doi: 10.1056/ NEJMoa010806.

3. Wang YA, Sullivan EA, Black D, Dean J, Bryant J, Chapman M. Preterm birth and low birth weight after assisted reproductive technology-related pregnancy in Australia between 1996 and 2000. Fertil Steril. 2005; 83: 1650-8. doi: 10.1016/j.fertnstert.2004.12.033.

4. Kurinczuk JJ, Hansen M, Bower C. The risk of birth defects in children born after assisted reproductive technologies. Curr Opin Obstet Gynecol. 2004; 16: 201-9.

5. Olson CK, Keppler-Noreuil KM, Romitti PA, Budelier WT, Ryan G, Sparks AE, Van Voorhis BJ. In vitro fertilization is associated with an increase in major birth defects. Fertil Steril. 2005; 84: 1308-15. doi: 10.1016/j. fertnstert.2005.03.086.

6. Dunietz GL, Holzman C, McKane P, Li C, Boulet SL, Todem D, Kissin DM, Copeland G, Bernson D, Sappenfield WM, Diamond MP. Assisted reproductive technology and the risk of preterm birth among primiparas. Fertil Steril. 2015; 103: 974-9 e1. doi: 10.1016/j.fertnstert.2015.01.015.

7. Zhong X, Jiang YZ, Liu P, He W, Xiong Z, Chang W, Zhu J, Cui Q. Toll-like 4 receptor /NFkappaB inflammatory/ miR-146a pathway contributes to the ART-correlated preterm birth outcome. Oncotarget. 2016; 7:72475-72485. doi: 10.18632/oncotarget.11987.

8. Hansen M, Bower C, Milne E, de Klerk N, Kurinczuk JJ. Assisted reproductive technologies and the risk of birth defects--a systematic review. Hum Reprod. 2005; 20: 32838. doi: 10.1093/humrep/deh593.

9. Hansen M, Kurinczuk JJ, Milne E, de Klerk N, Bower C. Assisted reproductive technology and birth defects: a systematic review and meta-analysis. Hum Reprod Update. 2013; 19: 330-53. doi: 10.1093/humupd/dmt006.

10. Ansari RM. Potential use of durian fruit (Durio zibenthinus Linn) as an adjunct to treat infertility in polycystic ovarian syndrome. J Integr Med. 2016; 14: 22-8. doi: 10.1016/ S2095-4964(16)60240-6.

11. Luke S, Sappenfield WM, Kirby RS, McKane P, Bernson D, Zhang Y, Chuong F, Cohen B, Boulet SL, Kissin DM. The Impact of ART on Live Birth Outcomes: Differing Experiences across Three States. Paediatr Perinat Epidemiol. 2016; 30: 209-16. doi: 10.1111/ppe.12287.

12. Hargreave M, Jensen A, Toender A, Andersen KK, Kjaer SK. Fertility treatment and childhood cancer risk: a systematic meta-analysis. Fertil Steril. 2013; 100: 150-61. doi: 10.1016/j.fertnstert.2013.03.017.

13. Sauber-Schatz EK, Sappenfield W, Grigorescu V, Kulkarni A, Zhang Y, Salihu HM, Rubin LP, Kirby RS, Jamieson DJ, Macaluso M. Obesity, assisted reproductive technology, and early preterm birth--Florida, 2004-2006. Am J Epidemiol. 2012; 176: 886-96. doi: 10.1093/aje/kws155.

14. Tepper NK, Farr SL, Cohen BB, Nannini A, Zhang Z, Anderson JE, Jamieson DJ, Macaluso M. Singleton preterm birth: risk factors and association with assisted reproductive technology. Matern Child Health J. 2012; 16: 807-13. doi: 10.1007/s10995-011-0787-8.

15. Xu XK, Wang YA, Li Z, Lui K, Sullivan EA. Risk factors associated with preterm birth among singletons following assisted reproductive technology in Australia 2007-2009-a population-based retrospective study. BMC Pregnancy Childbirth. 2014; 14: 406. doi: 10.1186/s12884-014-0406-y.

16. Zhang YP, Liu XH, Gao SH, Wang JM, Gu YS, Zhang JY, Zhou X, Li QX. Risk factors for preterm birth in five Maternal and Child Health hospitals in Beijing. PLoS One. 2012; 7: e52780. doi: 10.1371/journal.pone.0052780.

17. Chen Y, Li G, Ruan Y, Zou L, Wang X, Zhang W. An epidemiological survey on low birth weight infants in China and analysis of outcomes of full-term low birth weight infants. BMC Pregnancy Childbirth. 2013; 13: 242. doi: 10.1186/1471-2393-13-242.

18. Yan J, Huang G, Sun Y, Zhao X, Chen S, Zou S, Hao C, Quan S, Chen ZJ. Birth defects after assisted reproductive technologies in China: analysis of 15,405 offspring in seven centers (2004 to 2008). Fertil Steril. 2011; 95: 458-60. doi: 10.1016/j.fertnstert.2010.08.024.

19. Heffner LJ. Advanced maternal age--how old is too old? N Engl J Med. 2004; 351: 1927-9. doi: 10.1056/ NEJMp048087.

20. Bray I, Gunnell D, Davey Smith G. Advanced paternal age: how old is too old? J Epidemiol Community Health. 2006; 60: 851-3. doi: 10.1136/jech.2005.045179.

21. Pantos K, Athanasiou V, Stefanidis K, Stavrou D, Vaxevanoglou T, Chronopoulou M. Influence of advanced age on the blastocyst development rate and pregnancy rate in assisted reproductive technology. Fertil Steril. 1999; 71: 1144-6.

22. Wang JX, Davies MJ, Norman RJ. Obesity increases the risk of spontaneous abortion during infertility treatment. Obes Res. 2002; 10: 551-4. doi: 10.1038/oby.2002.74.

23. Luke B, Brown MB, Stern JE, Missmer SA, Fujimoto VY, Leach R, Group SW. Female obesity adversely affects assisted reproductive technology (ART) pregnancy and live birth rates. Hum Reprod. 2011; 26: 245-52. doi: 10.1093/ humrep/deq306.

24. Dias PA, Guimaraes AB, Albuquerque Ade $\mathrm{O}$, de Oliveira KL, Cavalcante ML, Guimaraes SB. Short-term complementary and alternative medicine on quality of life in women with fibromyalgia. J Integr Med. 2016; 14: 29-35. doi: 10.1016/S2095-4964(16)60235-2.

25. Zhu XX, Yan YW, Chen D, Ai CZ, Lu X, Xu SS, Jiang S, Zhong GS, Chen DB, Jiang YZ. Long non-coding RNA HoxA-AS3 interacts with EZH2 to regulate lineage commitment of mesenchymal stem cells. Oncotarget. 2016; 7:63561-63570. doi: 10.18632/oncotarget.11538.

26. Check JH, Katsoff B, Wilson C, Choe JK, Brasile D. Pregnancy outcome following fresh vs frozen embryo transfer into gestational carriers using a simplified slow 
freeze protocol. Clin Exp Obstet Gynecol. 2012; 39: 23-4.

27. Evans J, Hannan NJ, Edgell TA, Vollenhoven BJ, Lutjen PJ, Osianlis T, Salamonsen LA, Rombauts LJ. Fresh versus frozen embryo transfer: backing clinical decisions with scientific and clinical evidence. Hum Reprod Update. 2014; 20: 808-21. doi: 10.1093/humupd/dmu027.

28. Li Z, Wang YA, Ledger W, Edgar DH, Sullivan EA. Clinical outcomes following cryopreservation of blastocysts by vitrification or slow freezing: a population-based cohort study. Hum Reprod. 2014; 29: 2794-801. doi: 10.1093/ humrep/deu246.

29. Weinerman R, Mainigi M. Why we should transfer frozen instead of fresh embryos: the translational rationale. Fertil Steril. 2014; 102: 10-8. doi: 10.1016/j. fertnstert.2014.05.019.
30. Boulet SL, Mehta A, Kissin DM, Warner L, Kawwass JF, Jamieson DJ. Trends in use of and reproductive outcomes associated with intracytoplasmic sperm injection. JAMA. 2015; 313: 255-63. doi: 10.1001/jama.2014.17985.

31. Kushnir VA, Barad DH, Gleicher N. Intracytoplasmic sperm injection and reproductive outcomes. JAMA. 2015; 313: 1672. doi: 10.1001/jama.2015.3115.

32. Morken NH. Preterm delivery in IVF versus ICSI singleton pregnancies: a national population-based cohort. Eur J Obstet Gynecol Reprod Biol. 2011; 154: 62-6. doi: 10.1016/j.ejogrb.2010.08.025. 